Marquette University

e-Publications@Marquette

\title{
The Sensitivity and Psychometric Properties of a Brief Computer- Based Cognitive Screening Battery in a Depression Clinic
}

\author{
Scott Aaron Langenecker \\ University of Michigan - Ann Arbor \\ Angela F. Caveney \\ University of Michigan - Ann Arbor \\ Bruno Giordani \\ University of Michigan - Ann Arbor \\ Elizabeth A. Young \\ University of Michigan - Ann Arbor \\ Kristy A. Nielson \\ Marquette University, kristy.nielson@marquette.edu
}

See next page for additional authors

Follow this and additional works at: https://epublications.marquette.edu/psych_fac

Part of the Psychology Commons

\section{Recommended Citation}

Langenecker, Scott Aaron; Caveney, Angela F.; Giordani, Bruno; Young, Elizabeth A.; Nielson, Kristy A.; Rapport, Lisa J.; Bieliauskas, Linas A.; Mordhorst, Matthew J.; Marcus, Sheila; Yodkovik, Naomi; Kerber, Kevin; Berent, Stanley; and Zubieta, Jon-Kar, "The Sensitivity and Psychometric Properties of a Brief Computer-Based Cognitive Screening Battery in a Depression Clinic" (2007). Psychology Faculty Research and Publications. 113.

https://epublications.marquette.edu/psych_fac/113 


\section{Authors}

Scott Aaron Langenecker, Angela F. Caveney, Bruno Giordani, Elizabeth A. Young, Kristy A. Nielson, Lisa J. Rapport, Linas A. Bieliauskas, Matthew J. Mordhorst, Sheila Marcus, Naomi Yodkovik, Kevin Kerber, Stanley Berent, and Jon-Kar Zubieta 


\section{The Sensitivity And Psychometric Properties Of A Brief Computer- Based Cognitive Screening Battery In A Depression Clinic}

Scott A. Langenecker

Department of Psychiatry, University of Michigan Medical Center, Ann Arbor, MI

Angela F. Caveney

Department of Psychiatry, University of Michigan Medical Center, Ann Arbor, MI

Bruno Giordani

Department of Psychiatry, University of Michigan Medical Center, Ann Arbor, MI

\section{Elizabeth A. Young}

Department of Psychiatry, University of Michigan Medical Center, Ann Arbor, MI

The Molecular and Behavioral Neuroscience Institute, Ann Arbor, MI Kristy A. Nielson Department of Psychology, Marquette University, Milwaukee, WI 


\title{
Lisa J. Rapport
}

Department of Psychology, Wayne State University, Detroit, $\mathrm{MI}$

\section{Linas A. Bieliauskas}

Department of Psychiatry, University of Michigan Medical Center, Ann Arbor, MI

Matthew J. Mordhorst

Department of Psychiatry, University of Michigan Medical Center, Ann Arbor, MI

\section{Sheila Marcus}

Department of Psychiatry, University of Michigan Medical Center, Ann Arbor, MI

\section{Naomi Yodkovik}

Department of Psychiatry, University of Michigan Medical Center, Ann Arbor, MI

Kevin Kerber

Department of Psychiatry, University of Michigan Medical Center, Ann Arbor, MI

Stanley Berent

Department of Psychiatry, University of Michigan Medical Center, Ann Arbor, MI

Jon-Kar Zubieta

Department of Psychiatry, University of Michigan Medical Center, Ann Arbor, MI

\begin{abstract}
At present, there is poor accuracy in assessing cognitive and vegetative symptoms in depression using clinician or self-rated measures, suggesting the need for development of standardized tasks to assess these functions. The current study assessed the psychometric properties and diagnostic specificity of a brief neuropsychological screening battery designed to assess core signs of depression; psychomotor retardation, attention and
\end{abstract}


executive functioning difficulties, and impaired emotion perception within an outpatient psychiatry setting. Three hundred eighty-four patients with mood disorders and 77 healthy volunteers participated. A large percentage of patients met diagnostic criteria for Major Depressive Disorder alone (49\%) or with another comorbid psychiatric disorder (24\%). A brief, 25-min battery of computer-based tests was administered to control participants and patients measuring the constructs of inhibitory control, attention, visual perception, and both executive and visual processing speed. The patient groups performed significantly worse than the control group regardless of diagnosis on visual perception and attention accuracy and processing speed factors. Surprisingly, the anxiety disorder group performed better than several other psychiatric disorder groups in inhibitory control accuracy. Developing valid and reliable measures of cognitive signs in mood disorders creates excellent opportunities for tracking cognitive status prior to initiation of treatment, and allows for reliable retest following treatment.

Keywords: Depression, Psychiatric disorders, Executive functioning, Attention, Affect perception, Cognitive screening, Computers

\section{I ntroduction}

The burgeoning field of evidence-based medicine is a catalyst for the development of objective instruments for diagnosing mental disorders and tracking symptoms. Cognitive symptoms in mood disorders such as impairments in attention, concentration, inhibitory control, psychomotor retardation, affect perception and interpersonal sensitivity are amenable to evaluation via these methods. Although computer-based cognitive screening has been increasingly employed in research (e.g., age-related disorders and head injury), application of these computer-based screening measures to psychiatric populations and clinical care has been sparse. The present study provides a prototype for the use of computer-based cognitive screening measures that can be administered and scored with minimal utilization of time and financial resources.

Measurement of specific cognitive deficits in depression and related disorders poses specific logistical problems when implemented in a clinical setting. For example, large clinical settings often do not have technicians (or enough technicians) available to administer complex, traditional neuropsychological tests, or the investment of resources needed to administer, score, and interpret these tests. Computer-based screening batteries, which can be readily translated for use in a depression clinic, can provide a meaningful, objective

Psychiatry Research, Vol 152, No. 2-3 (August, 2007): pg. 143-154. DOI. This article is @ Elsevier and permission has been granted for this version to appear in e-Publications@Marquette. Elsevier does not grant permission for this article to be further copied/distributed or hosted elsewhere without the express permission from Elsevier. 
benchmark to aid psychiatrists and other practitioners in deciding when a complete neuropsychological evaluation may be needed, or if a briefer consultation about the cognitive strengths and weaknesses would be of assistance with diagnosis and treatment (Simpson et al., 1989; Robbins et al., 1994; Letz et al., 1996a, b; Gur et al., 2001a,b;

Feiger et al., 2003). Many of the previously developed computer-based batteries used with other populations provide normative data from a large cohort of individuals, yet none have been specifically designed or validated for use with depressed patients. For example, batteries designed for older individuals use paradigms that are often far too easy, and thus insensitive, to difficulties specific to depression (Sweeney et al., 2000). In fact, a large number of these paradigms are used to distinguish between demented elderly and depressed elderly, with the goal of demonstrating no difficulties in the depressed elderly, clearly not the ideal parameters for use in psychiatric settings. Tasks designed for use in a depression clinic must possess adequate clinical relevance and psychometric accuracy, must be sensitive to weaknesses reported by patients, and must minimize the methodological challenges evident in prior research with tasks developed for use with other populations.

Some existing research suggests a continuum of cognitive dysfunction in depression and related mood disorders that closely matches the perceived disease severity, and perhaps the long-term prognosis of these disorders. For example, attention and executive functioning deficits noted in bipolar disorder are often more severe than those observed in unipolar depression (Sweeney et al., 2000; Borkowska and Rybakowski, 2001). Furthermore, people with anxiety disorders rarely display any measurable cognitive difficulties, often outperforming those with other mood disorders and performing similarly to healthy controls (Gilboa-Schechtman et al., 2002). Some, however, have failed to demonstrate a distinction between mood disorders in cognitive functioning, suggesting that there are only small to modest effect sizes (Hoff et al., 1990; Franke et al., 1993). Therefore, studies with fewer participants may be underpowered to detect these differences. Length of illness, genetic predisposition, and medications may also affect performance on cognitive tests for those with various mood disorders (Kessing, 1998; Naismith et al., 2003; Martinez-Aran et al., 2004). Nonetheless, it is reasonable to

Psychiatry Research, Vol 152, No. 2-3 (August, 2007): pg. 143-154. DOI. This article is @ Elsevier and permission has been granted for this version to appear in e-Publications@Marquette. Elsevier does not grant permission for this article to be further copied/distributed or hosted elsewhere without the express permission from Elsevier. 
hypothesize that individuals with varying mood disorders may differ by both the extent and pattern of cognitive difficulty.

The current study presents the psychometric properties and diagnostic specificity of a brief neuropsychological screening battery designed to assess core signs of depression; psychomotor retardation, attention and executive functioning difficulties, and impaired emotion perception. It was expected that valid, reliable performance could be obtained on these tests, with factors matching core cognitive constructs of attention accuracy, inhibitory accuracy, emotion processing accuracy, and psychomotor speed, and that each derived factor would demonstrate strong internal reliability. Relationships between performance and symptoms, length of illness, and diagnostic subtype were also explored.

\section{Methods}

\subsection{Participants}

Consecutive patients (clinic patients, $n=332$ ) arriving for their first psychiatric appointment with a University of Michigan Depression Center treatment team were included in the study. Additional research participants, both control and depressed, were recruited through projects at the University of Michigan volunteers responding to flyers posted at the Medical Center ( $\operatorname{mood}$ disorder patients $n=52$, Control $n=43$ ) and Marquette University college undergraduates receiving course credit (Control $n=34$ ). As described in detail below, four control participants and 17 patients did not perform with valid cognitive data leaving a total of 73 participants in the control group and 367 participants in the patient group. Only patients and controls who demonstrated valid data were included in all statistical analyses. The Institutional Review Boards (IRB) at each respective institution approved the corresponding study protocol. After complete description of the study to the participants, written informed consent was obtained from research participants. Clinic data from patients was deidentified with an IRB approved waiver of informed consent for this data. The diagnostic breakdown and demographic characteristics for the participants are provided in Table 1.

Psychiatry Research, Vol 152, No. 2-3 (August, 2007): pg. 143-154. DOI. This article is @ Elsevier and permission has been granted for this version to appear in e-Publications@Marquette. Elsevier does not grant permission for this article to be further copied/distributed or hosted elsewhere without the express permission from Elsevier. 
NOT THE PUBLISHED VERSION; this is the author's final, peer-reviewed manuscript. The published version may be accessed by following the link in the citation at the bottom of the page.

Table 1. Demographic information for diagnostic groups

\begin{tabular}{|c|c|c|c|c|c|}
\hline Diagnosis code & $\begin{array}{l}\mathbf{N} / \mathbf{N} \\
\text { valid }\end{array}$ & $\begin{array}{c}\% \\
\text { Female }\end{array}$ & $\begin{array}{c}\% \text { Taking } \\
\text { medications }\end{array}$ & $\begin{array}{c}\text { Age } \\
\text { M (S.D.) }\end{array}$ & $\begin{array}{c}\text { Education } \\
\text { M (S.D.) }\end{array}$ \\
\hline $\begin{array}{l}\text { Major depression } \\
\text { (MDD) }\end{array}$ & $188 / 179$ & 73.9 & 60.6 & $35.5(12.1)$ & $15.4(2.8)$ \\
\hline MDD and anxiety & $62 / 59$ & 63.0 & 70.0 & $35.8(10.8)$ & $15.5(2.6)$ \\
\hline MDD and dysthymia & $29 / 27$ & 65.6 & 48.3 & $35.5(11.1)$ & $16.2(2.9)$ \\
\hline Dysthymia & $6 / 6$ & 83.3 & 66.7 & $42.2(13.8)$ & $16.5(1.8)$ \\
\hline Bipolar & $25 / 24$ & 60.0 & 96.0 & $35.8(9.6)$ & $15.7(2.8)$ \\
\hline Mood disorder NOSạ & $12 / 11$ & 50.0 & 50.0 & $35.6(14.4)$ & $15.1(3.6)$ \\
\hline Adjustment $\underline{a}$ & $12 / 12$ & 83.3 & 58.3 & $35.1(12.5)$ & $15.9(1.8)$ \\
\hline $\begin{array}{l}\text { Generalized } \\
\text { anxiety } \underline{\underline{b}}\end{array}$ & $19 / 19$ & 57.9 & 79.0 & $36.4(13.2)$ & $15.0(3.3)$ \\
\hline $\begin{array}{l}\text { Obsessive } \\
\text { compulsive }{ }^{\underline{b}}\end{array}$ & $5 / 5$ & 40.0 & 80.0 & $36.2(9.1)$ & $15.6(1.7)$ \\
\hline Panic $\underline{b}$ & $7 / 7$ & 85.7 & 62.5 & $33.1(10.6)$ & $13.0(1.9)$ \\
\hline Social phobia $\underline{\underline{b}}$ & $3 / 3$ & 0.0 & 66.7 & $39.3(19.6)$ & $14.7(3.1)$ \\
\hline None $e^{a}$ & $16 / 15$ & 68.8 & 31.3 & $29.3(6.8)$ & $14.6(3.1)$ \\
\hline Control & $77 / 73$ & 57.1 & 0.0 & $25.1(9.2)$ & $14.5(2.5)$ \\
\hline Total & 461 므/440 & 66.1 & 62.5 & 33.7 (11.9) & $15.3(2.7)$ \\
\hline
\end{tabular}

alncluded for psychometric analyses, excluded from group analyses due to small sample size.

${ }^{b}$ Combined into Anxiety disorder group.

*21 participants data excluded due to performance 2.5 standard deviations below each group mean on two easy tasks (e.g., Level 1 percent correct targets for the Parametric Go/No-go task and percent correct animal categorization for the Facial Emotion Perception Test).

Control participants were screened for depression using the Hamilton Rating Scale for Depression (HRSD, < 5, Hamilton, 1960, 1967), Beck Depression Inventory-II (BDI , < 6, Beck et al., 1988), and/or clinical interview. All mood disorder patients were diagnosed using DSM-IV criteria by board-certified psychiatrists $(n=362)$ or using the Structured Clinical Interview for DSM-IV ( $n=22$, First et al., 1995). Depression symptoms in clinic patients were assessed with the Personal Health Questionnaire (Kroenke et al., 2001). Current or past history of psychological or neurological problems in self or first degree relatives was ground for exclusion of control participants. Patients were excluded if there was a current or past diagnosis of psychosis or neurological disorder, a severe medical disorder that might be reasonably be expected to impact cognitive functioning (e.g., myocardial infarction), or current alcohol or substance abuse/dependence.

Psychiatry Research, Vol 152, No. 2-3 (August, 2007): pg. 143-154. DOI. This article is (C) Elsevier and permission has been granted for this version to appear in e-Publications@Marquette. Elsevier does not grant permission for this article to be further copied/distributed or hosted elsewhere without the express permission from Elsevier. 
NOT THE PUBLISHED VERSION; this is the author's final, peer-reviewed manuscript. The published version may be accessed by following the link in the citation at the bottom of the page.

\subsection{Materials}

\subsubsection{Synonym Knowledge task}

The Synonym Knowledge task (SKT; based on Shipley, 1946) was used as an estimate of verbal intelligence. It was expected that this would serve as a control task, with no differences between the groups. Participants were presented with a word and then asked to choose which of four additional words was most similar in meaning to the word first presented. There was no penalty for guessing and no time limit for responding.

\subsubsection{Facial Emotion Perception task}

The Facial Emotion Perception task (FEPT; Rapport et al., 2002; Langenecker et al., 2005) was used to assess accuracy and speed of recognition of facial expressions (e.g., impaired emotion perception) and animal categorization. The FEPT was used to assess emotion perception and processing, a domain of decreased functioning in depression and other mood disorders research (Gur et al., 1992; Mayberg et al., 1999; LeDoux, 2000). Participants were presented with and asked to rapidly categorize faces (from Ekman and Friesen, 1976) and animals. For the face trials, participants categorized the facial expression into one of four possibilities: happy, sad, angry, or fearful. For the animal trials, participants categorized the animal into one of four possibilities: dog, cat, primate, or bird. A stimulus is presented for $300 \mathrm{~ms}$, followed by a mask for $100 \mathrm{~ms}$, and then $2600 \mathrm{~ms}$ are provided as a response window. Trials are separated by the presentation of a cross for $500 \mathrm{~ms}$.

\subsubsection{Parametric Go/No-go task}

The Parametric Go/No-go (PGNG) task (Langenecker et al., 2005, based upon Garavan et al., 1999; Nielson et al., 2002; Langenecker and Nielson, 2003) was used to assess inhibitory control, attention and problem-solving abilities (e.g., attention and executive functioning, see Fig. 1) and associated brain areas also strongly implicated in depression research (Austin et al., 1999; Bush et al., 2000; Pizzigalli et al., 2001). The PGNG consist of a rapid

Psychiatry Research, Vol 152, No. 2-3 (August, 2007): pg. 143-154. DOI. This article is (C) Elsevier and permission has been granted for this version to appear in e-Publications@Marquette. Elsevier does not grant permission for this article to be further copied/distributed or hosted elsewhere without the express permission from Elsevier. 
(interstimulus interval $=500 \mathrm{~ms}$ ) serial presentation of alphabet letters, where targets are " $x$ ", " $y$ ", or " $z$ ". In the Go condition (Level $1)$, the participant is instructed to respond to any of the targets, regardless of the order of presentation. In the Two-target Go/No-go condition (Level 2), the participant responds the targets " $x$ " and " $y$ ", but only in alternation (non-repeating rule, see Fig. 1). The Three Target Go/No-go task (Level 3) includes all three targets, with the same non-repeating rule. As such, the working memory load for each inhibitory condition was minimal (2, 3 targets), while updating of the to-be-inhibited-target was important, as was control of impulsive responding to repeating targets. Therefore, two aspects of inhibitory control are measured (Hasher and Zacks, 1988); behavioral response inhibition (e.g., impulsivity), and removal inhibition (e.g., updating working memory rules or set-shifting). Finally, the PGNG provide for an assessment of psychomotor retardation, with three levels of cognitive load.

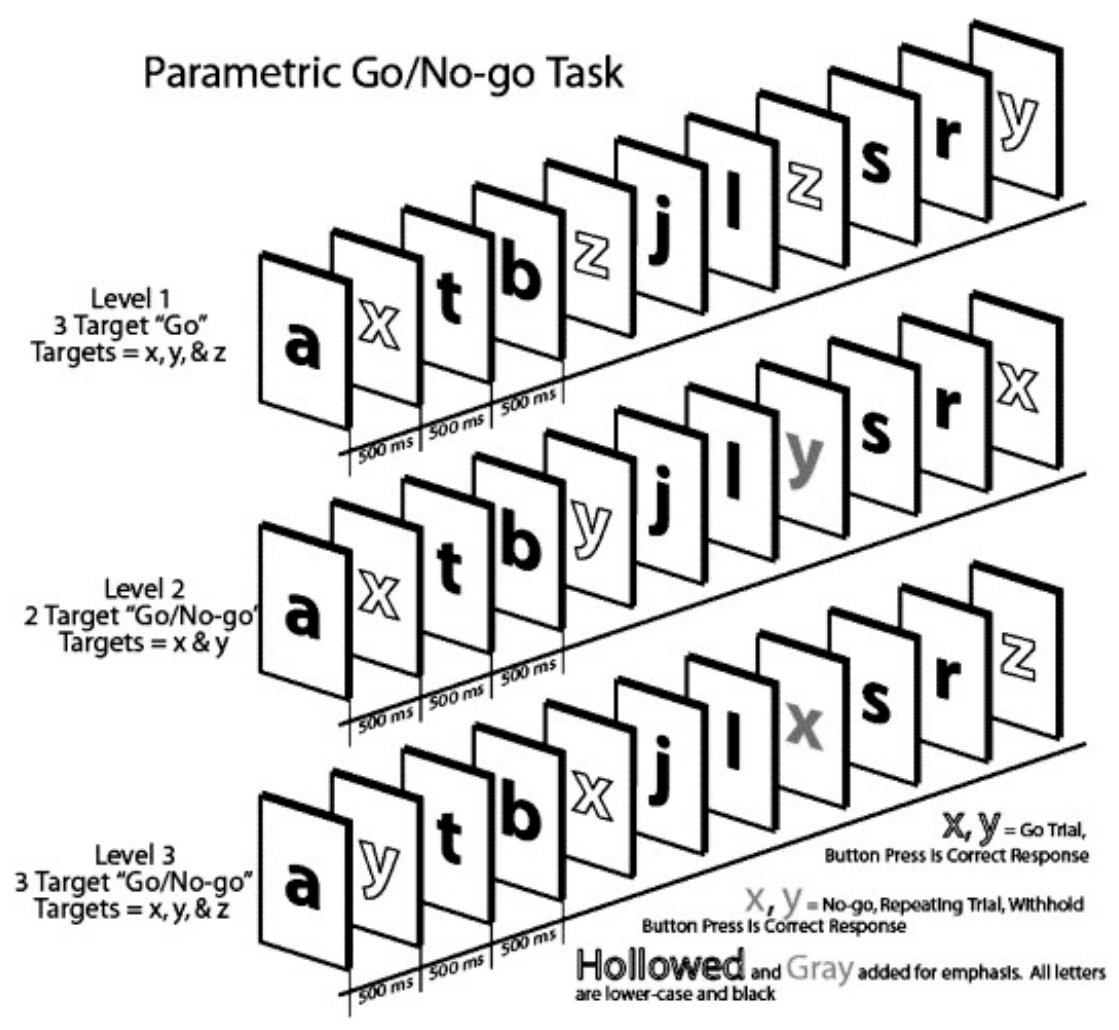

Fig. 1. The Go/No-go task illustration. The non-repeating rule is illustrated for Level 2 and Level 3 Go/No-go, while the Level 1, Go task requires responses to all target stimuli regardless of order. 


\subsection{Procedure}

After greeting the participant, an assistant explained that the project was designed to measure verbal ability, emotion perception, attention, and inhibition skills. The participant was assured that the task was not designed for perfect performance, nor was the screen designed as a thorough measure of cognitive functioning. Once the participant understood the procedure, the assistant then administered the three computer-based tasks.

\subsection{Statistical analyses}

Outliers in the data were truncated using a winsor procedure as outlined elsewhere (Tabachnik and Fidell, 2001). Descriptive statistics for the dependent variables were computed, including standard error of measurement. Groups were compared on demographic factors and appropriate corrections were made. A chi-square was computed to determine whether there were a disproportionate number of outlier data points for patients ( $n=367$ ) versus control $(n=73$ ) participants. A principal axis factor analysis (Control $n=73$, Patient $n=367$ ) with oblique rotation was computed with the executive and emotion processing dependent variables. Odd-even item reliability (with Spearman-Brown coefficients) was computed for each of the derived factors (Control $n=73$, Patient $n=367$ ). The relationship between illness, demographic characteristics and cognitive factors was also explored. A MANOVA was used to address hypothesized differences on the cognitive factors between the age-matched control $(n=42)$ and mood disorder $(n=367)$ groups.

\section{Results}

\subsection{Demographic characteristics}

The control group did not differ from the patient groups on education ( $F=1.10$, $\mathrm{df}=12,395, \mathrm{P}=0.31, \mathrm{E}^{2}=0.032$ ); or estimated IQ (from SKT, $F=1.16$, df $=12,373, P=0.31, E^{2}=0.036$ ). There were significant differences for age $(F=5.14$, df $=12,448$, $\left.P<0.0001, E^{2}=0.121\right)$; the control group was significantly younger than the patient groups (all $\mathrm{P}^{\prime} \mathrm{s}<0.04$ ). There were also more males

Psychiatry Research, Vol 152, No. 2-3 (August, 2007): pg. 143-154. DOI. This article is (C) Elsevier and permission has been granted for this version to appear in e-Publications@Marquette. Elsevier does not grant permission for this article to be further copied/distributed or hosted elsewhere without the express permission from Elsevier. 
in the control group compared to the entire mood disorder sample $\left(X^{-}=3.71, n=461, P=0.05\right)$, although several patient groups had nearly identical male/female ratios as the control group. The age and gender differences were controlled for by age-matching groups of mood disorder and control participants, and by removing a disproportionate percentage of young males from the sample (e.g., 18- and 19-year-old males, although some females from this age range were also removed). As a result, there were no differences between the age/gender-matched control group and the patient groups on age (control $M=29.5, S . D .=9.8, F=1.48$, df $=12,395$, $P=0.13, E^{2}=0.043$ ) or gender distribution ( $73.8 \%$ female, $\left.X^{-}=0.53, n=461, P=0.46\right)$.

\subsection{Descriptive statistics and measures of performance validity}

Descriptive statistics are presented for each dependent variable in Tables 1 and 2 . In general, simpler tasks tended to be more skewed. Validity of performance was determined using outlier criteria for each group (control, psychiatric separately), a combination of ascertaining deviance from the mean (e.g., 2.5 S.D.) and taking into consideration the distribution of scores (e.g., boxplot determination) on two easy tasks (Level 1 percent correct targets for the PGNG task and percent correct animal categorization for the Facial Emotion Perception Test). A chi-square comparing the number of out of range (e.g., invalid performance) variables between patient ( $n=367$ ) and control $(n=73)$ groups was not significant $\left(X^{-}=3.47, n=461\right.$, $P=0.99)$. The number of valid cases for each group, based upon psychometric deviance and performance probability on the cognitive tasks, is presented in Table 1. All participants with valid performance ( $n=440$ ) were used to assess the psychometric properties of the tasks and relationships with clinical variables (Sections 3.3-3.5), while only matched control and patient groups with more than 20 subjects were used to determine any subgroup differences (Section 3.6). Only the control group matched by age and gender to the patient groups was used to test this assumption, as age, and possibly gender, could have a significant impact on performance.

Psychiatry Research, Vol 152, No. 2-3 (August, 2007): pg. 143-154. DOI. This article is (C) Elsevier and permission has been granted for this version to appear in e-Publications@Marquette. Elsevier does not grant permission for this article to be further copied/distributed or hosted elsewhere without the express permission from Elsevier. 
NOT THE PUBLISHED VERSION; this is the author's final, peer-reviewed manuscript. The published version may be accessed by following the link in the citation at the bottom of the page.

Table 2. Psychometric statistics for dependent variables ${ }^{a}$

\begin{tabular}{|c|c|c|c|c|c|}
\hline \multirow{3}{*}{\multicolumn{2}{|c|}{$\begin{array}{l}\text { Descriptive statistics } \quad \text { M (S.D.) } \\
\text { Facial emotion perception task, } N=440\end{array}$}} & \multirow[t]{2}{*}{ Min. } & \multirow[t]{2}{*}{ Max. } & \multirow[t]{2}{*}{ Skewness } & \multirow[t]{2}{*}{ Kurtosis } \\
\hline & & & & & \\
\hline & & \multicolumn{4}{|c|}{ Accuracy } \\
\hline$\%$ Correct Animals & $92.2(10.7)$ & $58.0 \underline{\square}$ & 100.0 & -1.5 & 1.7 \\
\hline$\%$ Correct faces & $83.5(10.7)$ & $44.0 \underline{\square}$ & 100.0 & -1.5 & 2.5 \\
\hline \multicolumn{6}{|l|}{ Response time } \\
\hline Animals RT & $969.7(335.1)$ & $402.5 \underline{\square}$ & 1846.0 므 & 0.8 & 0.1 \\
\hline Faces RT & $1067.2(307.3)$ & 422.3 & 1832.0 므 & 0.7 & 0.1 \\
\hline Neutral faces RT & $1372.8(454.4)$ & $383.0 \underline{\square}$ & $2475.0 \underline{\square}$ & 0.3 & -0.1 \\
\hline \multicolumn{6}{|l|}{ Ambiguous stimuli } \\
\hline$\%$ Rated negatively & $80.8(25.9)$ & 0.0 & 100.0 & -1.4 & 1.1 \\
\hline \multicolumn{6}{|c|}{ Parametric Go/No-go Task, N = 440} \\
\hline Level 1 & $96.7(4.6)$ & $81.9 ㅁ ㅡ$ & 100.0 & -1.8 & 2.8 \\
\hline \multicolumn{6}{|c|}{ Attention, inhibition/updating working memory. Set-shifting, accuracy } \\
\hline Level 2 & $92.7(10.3)$ & 61.0 & 100.0 & -1.8 & 2.6 \\
\hline Level 3 & $83.0(12.6)$ & $46.0 \underline{\square}$ & 98.1 & -1.0 & 0.2 \\
\hline \multicolumn{6}{|c|}{ Inhibitory control accuracy } \\
\hline Level 2 & $79.2(18.4)$ & $25.0 \underline{\square}$ & 100.0 & -1.1 & 0.8 \\
\hline Level 3 & $69.4(18.8)$ & $23.0 \square$ & 100.0 & -0.4 & -0.4 \\
\hline \multicolumn{6}{|l|}{ Response time } \\
\hline Level 1 & $461.6(50.7)$ & 360.3 & $602.0 \square$ & 0.8 & 0.5 \\
\hline Level 2 & $462.7(67.3)$ & 335.9 & 649.0 므 & 1.0 & 0.8 \\
\hline Level 3 & $530.1(73.2)$ & 354.3 & $750.0 \underline{\underline{ }}$ & 0.7 & 0.5 \\
\hline \multicolumn{6}{|c|}{ Synonym knowledge, $\mathrm{N}=383$} \\
\hline$\%$ Correct & $70.5(13.5)$ & 8.0 & 95.0 & -1.2 & 2.5 \\
\hline
\end{tabular}

RT = response time; S.D. = standard deviation; Level $1=$ Three-target level of the Parametric Go/No-go test; Level 2 = two-target level of the Parametric Go/No-go test; Level $3=$ three-target level of the Parametric Go/ No-go test.

avalid performance data only.

*Outlier/winsor threshold.

\subsection{Factor analysis and reliability}

A principal axis factor analysis (control $n=73$ and patient $\mathrm{n}=367$ ) with oblique rotation was computed to determine whether there were separate constructs for emotion processing and executive functioning. As can be seen in Table 3, a five-factor solution was extracted. Three of these factors were entirely comprised of the PGNG variables and the remaining two included facial emotion perception variables (Table 3 ). The two processing speed factors $(r=0.42$, $\mathrm{P}<0.001$ ) were moderately correlated. As can be seen from the

Psychiatry Research, Vol 152, No. 2-3 (August, 2007): pg. 143-154. DOI. This article is (C) Elsevier and permission has been granted for this version to appear in e-Publications@Marquette. Elsevier does not grant permission for this article to be further copied/distributed or hosted elsewhere without the express permission from Elsevier. 
correlation matrix included in Table 4, there was little shared variance in accuracy factors for the Go/No-go and FEPT tasks. Eigenvalues, variance for each factor (total $=68 \%$ ), odd-even item reliability and Spearman-Brown coefficients are included in Table 4. SpearmanBrown coefficients for four of the five factors (Visual-Perceptual Processing Speed, Inhibitory Processing Speed, Attention and Set Shifting Accuracy, Visual-Perceptual Accuracy) ranged from 0.87 to 0.95, with the Inhibitory Accuracy factor coefficient at 0.67. Thus, the factors match accepted constructs and have good to excellent reliability.

Table 3. Factor structure for the parametric Go/No-go task and the facial emotion perception task ${ }^{\underline{a}}$

1.

Accuracy (\% correct-

$\mathrm{PC})$

PC Animals

PC Faces

Level 1 PC Targets

Level 2 PC Targets

Level 2 PC Inhibitions

Level 3 PC Targets

Level 3 PC Inhibitions

Neutral stimuli

\% Ranked negatively

Response time (RT)

Animals RT

Faces RT

Neutral Faces RT

Level 1 RT

Level 2 RT

0.74

(0.82)

0.94

0.65

(0.59)

2.

3.

4.

5.

0.63

0.65

$(-0.75)$

0.39

$(0.43)$

0.39

(0.47)

0.48

(0.50)

0.81

$(0.80)$

0.59

0.63

(0.67)

0.84

(0.87)

Level 3 RT

0.96

(0.90)

Psychiatry Research, Vol 152, No. 2-3 (August, 2007): pg. 143-154. DOI. This article is (C) Elsevier and permission has been granted for this version to appear in e-Publications@Marquette. Elsevier does not grant permission for this article to be further copied/distributed or hosted elsewhere without the express permission from Elsevier. 
Principal Axis Factoring. Oblimin Rotation. 1. Visual-Perceptual Processing Speed, 2. Inhibitory Processing Speed, 3. Attention Accuracy, 4. Inhibitory Accuracy, 5. VisualPerceptual Accuracy. Level $1=$ three target Go, Level $2=$ two target Go/No-go, Level $3=$ three target Go/No-go. Values are factor loadings from the pattern matrix, with values less than 0.30 are omitted for ease in reading the table. $\mathrm{N}=440$. aFactor structure is identical for two (factors 1 and 2 for response time) and three (factors 3 through 5 for accuracy variables) factor solutions if response time and accuracy variables are entered separately. Loadings from the two separate factor analyses are included in parentheses for comparison.

Table 4. Factor correlation matrix, eigenvalues, \% variance, and reliability statistics

\section{Factor}

1. Visual-perceptual processing speed

2. Inhibitory processing speed

3. Attention accuracy

4. Inhibitory control accuracy

5. Visual-perceptual accuracy

Factor statistics

Eigenvalues

$\%$ Variance

Reliability

Spearman-Brown

Odd-even $r$
1. 2.

3.

4.

5.

$-\quad 0.42^{\square \square}$

$0.32 \square$

$0.38 \square \square$

$0.11^{\square}$

0.01

$0.43^{\square \square}$

$-$

$0.15^{\text {미 }}$

0.31 प्र

$0.43^{\square \square}$

$-\quad 0.13^{\square \square}$

$-$

$\begin{array}{lllll}4.3 & 1.7 & 1.4 & 1.2 & 1.0 \\ 30.7 & 11.8 & 9.7 & 8.9 & 6.9\end{array}$

$0.95 \quad 0.95$

0.94

0.67

0.87

$\begin{array}{ll}0.91 & 0.91\end{array}$

0.88

0.50

0.78

${ }^{*} \mathrm{P}<0.005, \quad \square \mathrm{P}<0.0001, \mathrm{~N}=440$. Odd-even correlations are for odd and even items from the FEPT and PGNG tasks. \% Variance lists the unique variance for each of the factors derived from the principal axis factor analysis. Spearman-Brown correction is a correction for split-half reliability, controlling for loss of half of the items in the scale through odd-even split reliability.

\subsection{Clinical characteristics}

Both patient groups (i.e., clinic and volunteer patients) had moderate symptoms of depression (clinic patients $n=317$, PHQ- 9 $M=13.5$, S.D. $=6.3$, patient volunteers $n=39$, HRSD-17 $M=15.5$ and S.D. $=6.2, \mathrm{BDI}-\mathrm{II} \mathrm{M}=21.3, \mathrm{~S} . \mathrm{D} .=10.8)$. When comparing clinic patients and volunteers with psychiatric illness, the only difference between the two groups, of all demographic and cognitive variables, was on the Attention and Set-Shifting Accuracy factor (see below), on which clinic patients performed significantly worse than the patient volunteers $\left(F=5.6\right.$, df $\left.=1,401, P=0.018, E^{2}=0.014\right]$. The average age of onset was 23 years (S.D. $=11.4$ ), with mean symptom duration of 12.3 years (S.D. $=11.5$ ). Increasing depression symptoms (BDI-II, HRSD, PHQ-9) were associated with decreased attention and 
set shifting accuracy (BDI-II $n=69, r=-0.30, P=0.013$, HRSD $\mathrm{n}=72, \mathrm{r}=-0.26, \mathrm{P}=0.026$, but not PHQ-9 $\mathrm{n}=271, \mathrm{r}=-0.12$, $P=0.053)$, slower visual processing speed (BDI-II $n=69, r=-0.28$, $\mathrm{P}=0.021$, HRSD $\mathrm{n}=72, \mathrm{r}=-0.29, \mathrm{P}=0.014$, PHQ-9 $\mathrm{n}=271$, $r=-0.05, P=0.384$ ), decreased inhibitory control (PHQ-9 only $\mathrm{n}=271, \mathrm{r}=-0.14, \mathrm{P}=0.027)$ and slower inhibitory processing speed (PHQ-9 only $n=271, r=-0.17, P=0.005$ ). Age of onset and years of illness ( $n=283$ for all correlations) were significantly correlated with visual spatial accuracy $(r=-0.22, P=0.0001$ and $r=-0.15, P=0.014$, respectively), visual spatial processing speed ( $r=0.27, P=0.0001$ and $r=0.18, P=0.002$, respectively), and inhibitory processing speed $(r=0.12, P=0.038$ and $r=0.26$, $P=0.0001$, respectively), while attention accuracy was significantly negatively correlated with years of illness only $(r=-0.04, P=0.52$ and $r=-0.22, P=0.0001$, respectively). No correlations between symptoms, clinical characteristics and cognitive performance levels remained significant when age and education were covaried. All factors except Inhibitory Accuracy $(r=0.00, P=0.99)$ were significantly correlated with age ( $r^{\prime} s<-0.24$, $P^{\prime} s<0.0001$ ) and all factors except inhibitory processing speed $(r=0.02, P=0.68)$ were significantly correlated with education (all r's $>0.11$, P's < 0.03).

\subsection{Medication effects}

Differences in psychotropic medication status are noted between the patient diagnostic groups listed in Table 1 ( $X^{-}=25.7, n=384$, $P<0.007$ ). Several groups (Bipolar Disorder 97\%, Generalized Anxiety Disorder 79\%, Obsessive Compulsive Disorder $80 \%$, and Comorbid Depression and Anxiety 66\%) were more likely to be taking psychotropic medications at intake when compared to other groups (None, 31\%, Mood Disorder NOS 50\%, Comorbid Depression and Dysthymia, 48\%). Medication-free volunteers were recruited specifically for one of the research studies. As such, it was expected that the patient volunteers (54\%) would be more likely to be medication free compared to the clinic patients $\left(36 \%, \mathrm{X}^{-}=6.2\right.$, $\mathrm{n}=367, \mathrm{P}=0.01$ ). Medications taken were from 10 different classes (1. benzodiazepines and similar, 2. opiates, 3. non-opiate pain medications, 4. stimulants, 5. selective 5HT1 and 5HT2 agents, 6. selective serotonin and neuroepinephrine re-uptake inhibitors, 7.

Psychiatry Research, Vol 152, No. 2-3 (August, 2007): pg. 143-154. DOI. This article is @ Elsevier and permission has been granted for this version to appear in e-Publications@Marquette. Elsevier does not grant permission for this article to be further copied/distributed or hosted elsewhere without the express permission from Elsevier. 
tricyclics, 8. lithium, 9. mood stabilizers, and 10. atypical antipsychotics). Those patients currently taking medications performed more poorly only on the Inhibitory Accuracy Factor ( $t=2.09$, $\mathrm{df}=364, \mathrm{P}<0.04)$. No differences were found for the other factors (all t's $<1.5$ and P's $>0.15$ ). Future studies with larger sample sizes are needed to address any cognitive side-effects of medication type as the current study was underpowered to do so (many patients were taking multiple medications, confounded by severity and type of illness-non-random prescriptions).

\subsection{Performance differences between mood disorder and control groups}

It was expected that performance differences would exist between the control $(n=42)$ group and the diagnostic subgroups $(n=323)$. It was also expected that cognitive dysfunction would be greater in those diagnostic subgroups with more severe mood disorders (e.g., dual diagnosis, bipolar disorder) as a marker of psychiatric severity compared to less severe mood disorders. A MANOVA was computed with diagnostic code as the independent variable and performance in the respective cognitive factors as dependent variables. Due to small numbers and lack of differences in cognitive performance between the anxiety disorder groups (Social Phobia, Generalized Anxiety, Panic Disorder, and Obsessive Compulsive Disorder, all F's $<1.34$, P's $>0.28$ ), they were combined.

When comparing all the mood groups (MDD, Anxiety, Bipolar, comorbid MDD/Dysthymia, comorbid MDD/Anxiety) to each other and to the matched control group, the main effect for cognitive performance was significant $\left(F=1.57, P=0.04, E^{2}=0.021\right)$. Post hoc analyses (Fig. 2) indicated that the matched control group performed better than several patient groups (MDD, $P=0.007$, Anxiety $\mathrm{P}=0.052$, comorbid MDD/Dysthymia, $\mathrm{P}=0.037$, and comorbid MDD/Anxiety, $P=0.026$ ) on Visual-Perception Accuracy and VisualPerceptual Processing Speed (MDD, $P=0.027$, Bipolar Disorder, $\mathrm{P}=0.016$, and comorbid MDD/Anxiety, $\mathrm{P}=0.033$ ). For Inhibitory Control Accuracy, the Anxiety Disorders group performed better than the Bipolar $(P=0.017)$ and MDD/Dysthymia $(P=0.028)$ groups. The matched control group performed better than all patient groups (all

Psychiatry Research, Vol 152, No. 2-3 (August, 2007): pg. 143-154. DOI. This article is @ Elsevier and permission has been granted for this version to appear in e-Publications@Marquette. Elsevier does not grant permission for this article to be further copied/distributed or hosted elsewhere without the express permission from Elsevier. 
P's < 0.003) on Attention and Set-Shifting Accuracy. The cognitive tests and derived factors selected for this screening battery are sensitive to attention, executive functioning, emotion processing, and psychomotor functioning in mood disorders.
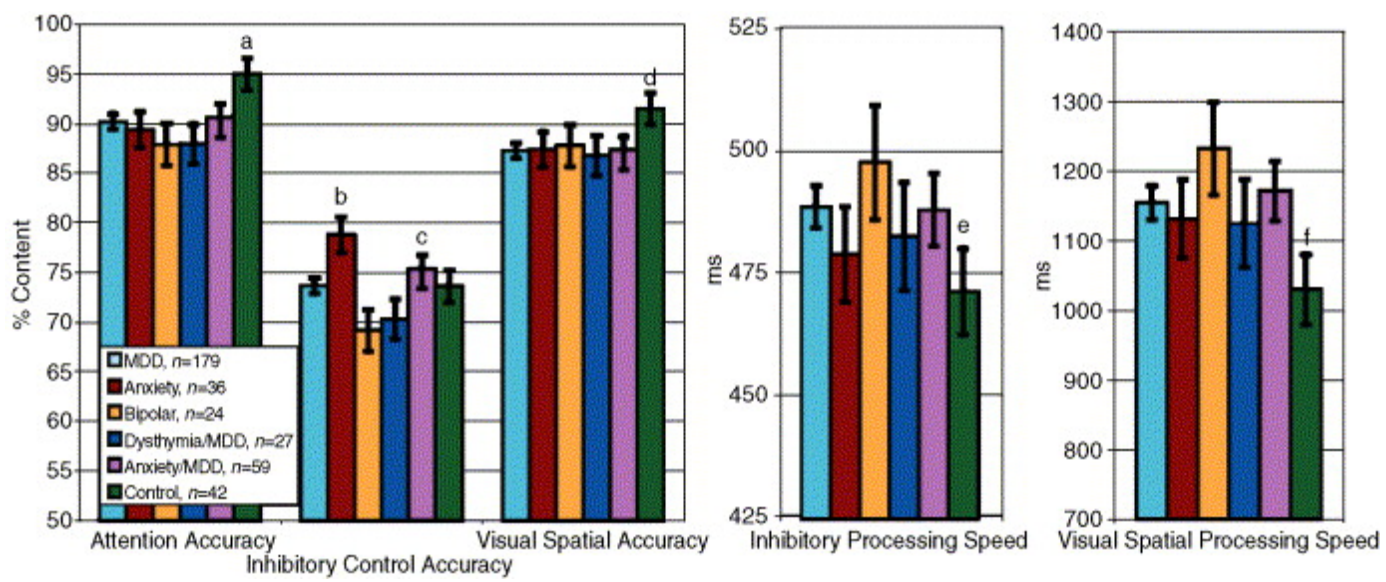

Fig. 2. Factor scores for cognitive factors comparing psychiatric subgroups, matched to control participants. $\mathrm{P}$ values are included in parentheses. ${ }^{\text {aThe }}$ matched control group performed better than all patient groups (all P's $<0.003$ ) on the Attention and Set-Shifting Accuracy factor. ${ }^{b}$ For the Inhibitory Control Accuracy factor, the Anxiety Disorders group performed better than the MDD $(P=0.069)$, Bipolar $(P=0.017)$, and MDD/Dysthymia ( $P=0.028)$ groups. The comorbid MDD/Anxiety group performed marginally better than the Bipolar group $(\mathrm{P}=.088)$ on the Inhibitory Control factor. dThe matched control group performed better than all patient groups except the Bipolar group on the Visual Perception Accuracy Factor (MDD, $P=0.007$, Anxiety $\mathrm{P}=0.052, \mathrm{MDD} / \mathrm{Dysthymia}, \mathrm{P}=0.037$, and MDD/Anxiety, $\mathrm{P}=0.026)$. ${ }^{\mathrm{e}}$ The matched control group performed marginally faster than the MDD $(P=0.077)$ and the Bipolar $(P=0.079)$ groups on the Inhibitory Processing Speed factor. The matched control group also outperformed several patient groups on the Visual-Perceptual Processing Speed factor (MDD, $\mathrm{P}=0.027$, Bipolar Disorder, $\mathrm{P}=0.016$, MDD/Anxiety, $\mathrm{P}=0.033$ ).

In order to better test the hypothesis that emotion processing is impaired in mood disorders, the two variables that comprise the Visual-Perception Accuracy factor were analyzed in a second posthoc MANOVA. This MANOVA compared the matched control and different diagnostic groups with the scores on face emotion and animal perception as the dependent variables. The control group performed better than the MDD $(P=0.014, P=0.033)$ and comorbid $\mathrm{MDD} /$ dysthymia $(P=0.062, P=0.088$ ) groups in facial emotion perception and animal categorization variables, respectively, and better than the Anxiety $(P=0.026)$ and comorbid MDD/Anxiety $(P=0.021)$ groups in animal categorization. 
NOT THE PUBLISHED VERSION; this is the author's final, peer-reviewed manuscript. The published version may be accessed by following the link in the citation at the bottom of the page.

\section{Discussion}

This study demonstrated that, using the present computerbased screening battery, reliable and objective information can be gathered with fairly minimal investment of time and resources. The battery was designed specifically for use with a psychiatric population in an outpatient setting. Therefore, in the future, the battery might be used as a screening tool in primary psychiatry and family medicine clinics to indicate who may benefit from a more comprehensive evaluation. The battery might also be used to determine when consultations with a neuropsychologist may be beneficial to interpret poor performance and to assist in managing cognitive weaknesses.

Evaluation of the validity of performance was important, as concerns about quantifying valid versus invalid data are particularly salient when employing computer-based cognitive testing (Gur et al., $2001 a, b$ ). Over $95 \%$ of participants performed within the valid range on the FEPT and Go/No-go tasks, supporting the hypothesis that valid data could be generated using the computer-based battery. As another mechanism for assessing validity of performance, performance on a synonym knowledge task was included in the battery (Cohen et al., 1982; Ellis et al., 1989). As anticipated, the patient and control groups did not differ on this measure. Similar performance levels on the synonym knowledge task across groups suggest that effort was equivalent for these groups as well. This finding is particularly important given the known performance challenges in depression (e.g., poor motivation, Rohling et al., 2002). These findings also suggest that visual motor ability was not the main reason for differences between groups on the cognitive factors of interest.

A factor analysis was also conducted to determine the nature and soundness of the psychometric properties of the tasks. It was expected that the factors would map onto known cognitive constructs and demonstrate good reliability. From the results, it was clear that the two primary tasks (Go/No-go and FEPT) were largely independent of each other in terms of the cognitive substrates underlying performance. Each of the factors demonstrated moderate to strong reliability. The relationship between the visual-perceptual accuracy and attention and set-shifting accuracy factors was modest. Likewise,

Psychiatry Research, Vol 152, No. 2-3 (August, 2007): pg. 143-154. DOI. This article is @ Elsevier and permission has been granted for this version to appear in e-Publications@Marquette. Elsevier does not grant permission for this article to be further copied/distributed or hosted elsewhere without the express permission from Elsevier. 
the relationship between response time factors for the Parametric Go/No-go and Facial Emotion Perception tasks were also modest. Inverse relationships between response time and accuracy factors for each of these tasks was in line with standard response time/accuracy trade-offs (Gur et al., 2001b). I nhibitory accuracy was a highly independent factor, suggesting that it is not synonymous with attention or set-shifting skills. Although not within the purview of the present study, the lack of a significant relationship between the attention/set-shifting factor and the inhibitory control factor supports the contention that there are separate executive functions as opposed to one executive function multiprocessor. In addition, the separation of attention and inhibitory factors as separate constructs is consistent with our prior work (Miller et al., 2004).

It was also expected that cognitive dysfunction would exist along a continuum from no impairment in the control group, mild dysfunction in the less severe diagnostic subgroups, and more significant cognitive impairment in persons with more severe disorders. This hypothesis was not supported as there were cognitive difficulties in almost all of the patient groups. The executive functioning and emotion processing difficulties found in MDD, disorders comorbid with MDD, and Bipolar disorder are consistent with prior work (Gur et al., 1992, 2001a; Lemelin et al., 1996; Langenecker et al., 2005). However, closer inspection of Fig. 2 shows that the Bipolar group was slower and less accurate on the PGNG compared to the other groups.

One striking result from the present study was the difference in performance of the anxiety disorders group on inhibitory control accuracy, on which they outperformed all other groups. Careful inspection of performance on the attention and inhibitory control factors suggests that the anxiety disorders group may have been willing to sacrifice errors of omission to avoid errors of commission, consistent with prior reports of hypervigilance in this group (Nutt, 2001). This suggests that response profiles may be useful in distinguishing between persons with primary anxiety and mood disorders.

Illness and demographic factors were also found to be associated with cognitive functioning. Most notably, increasing

Psychiatry Research, Vol 152, No. 2-3 (August, 2007): pg. 143-154. DOI. This article is @ Elsevier and permission has been granted for this version to appear in e-Publications@Marquette. Elsevier does not grant permission for this article to be further copied/distributed or hosted elsewhere without the express permission from Elsevier. 
symptom severity, age, age of onset, and years of illness were significantly negatively related to performance on the attention and set-shifting accuracy factor, consistent with prior cross sectional results. Slowed processing speed on the FEPT and PGNG were related with increasing symptom severity and age, but not age of onset or years of illness. If age is entered as a covariate in partial correlations, none remained significant, particularly as age of onset and years of illness are positively related to current age. Studies with larger samples are needed to better assess age and age of onset confounds through patient-to-patient matching.

Despite strong interest over the past two decades, findings of attention and executive functioning difficulties in depression and related disorders have not been consistently reported (Lemelin et al., 1996; Schatzberg et al., 2000; Williams et al., 2000; Gotlib et al., 2004; Langenecker et al., 2005). The present study demonstrates that on measures of sustained attention and set-shifting, a number of patient groups performed significantly poorer than the control group. A recent study has reported decreased behavioral activation in depressed patients, which might be analogous to the decreased performance on the attention and set-shifting factor, or target responses (Kasch et al., 2002). Contrary to expectation, there was little evidence of difficulties with impulse control in the patient groups in the present study. Kasch et al. (2002) reported similar findings of increased behavioral inhibition in patients with depression, which would likely result in increased inhibitory control performance.

Depression and related disorders have long been viewed as absent of cognitive impairment and have been traditionally referred to as "functional" disorders. However, a number of studies, including the present results, suggest that this view is premature (Hale, 1998; Dunkin et al., 2000). Many of the measures used in the past as an aid in screening for dementia were specifically designed to elicit intact performance in those with mood disorders. Not surprisingly, a number of these instruments are relatively insensitive to deficits in executive functioning, attention and emotion perception difficulties in depression and related groups (Gold et al., 1999; Hobart et al., 1999; Gur et al., 2001a; Dickerson et al., 2004; Boustani et al., 2005). Furthermore, many of the previously designed computer-screening measures do not measure emotion perception and processing, which are rapidly

Psychiatry Research, Vol 152, No. 2-3 (August, 2007): pg. 143-154. DOI. This article is @ Elsevier and permission has been granted for this version to appear in e-Publications@Marquette. Elsevier does not grant permission for this article to be further copied/distributed or hosted elsewhere without the express permission from Elsevier. 
emerging as key components of mood disorders and have, along with executive functioning tasks, been shown to predict treatment response (Hale, 1998; Dunkin et al., 2000; Kampf-Sherf et al., 2004).

One limitation of the current study was the age difference between the control group and the patient groups. However, this issue was addressed by removing a number of the younger control participants from the analysis and then comparing age-matched control and patient groups on the cognitive tests. One possible agerelated explanation for the present findings is thus removed by agematching. For example, if unmatched for age, there is the potential for an interaction between age and psychiatric status to confound the results of cognitive performance. For example, declines in visual acuity and visual perceptual abilities are reported with age in older samples than the current sample (Fisk and Rogers, 1991; Madden et al., 2004; Cabeza et al., 2004). As there were only 25 participants over the age of 55, a very conservative threshold for the onset of significant agerelated cognitive decline, there is little to no possibility that age is a relevant factor in the present results. Some might also consider the lack of a verbal memory measure in the current study a limitation. The focus of the current screening measures was on cores signs of depression, including psychomotor retardation, attention and executive functioning difficulties, and impaired emotion perception, rather than verbal memory. However, for additional utility, future studies might add it into the screening battery.

Another limitation of the present sample is that the patients were largely selected from a tertiary care clinic and may be more severe than those seen in regular clinical settings. The average length of illness for this group was 13 years, which may truly represent a more chronic, severe sample. Finally, brief batteries such as the one used in the present sample do not allow for a traditional, more thorough assessment of multiple cognitive domains. We acknowledge the tension between speed and breadth, and note that a screening battery should be sensitive, which appears to be the case here, and necessarily sacrifices breadth and depth for speed. As a large percentage of the mood disorders patients exhibited difficulty with these screening measures, it is likely that few with significant cognitive difficulties would be missed by such a screen, which is an important consideration, if beyond the purview of the present study.

Psychiatry Research, Vol 152, No. 2-3 (August, 2007): pg. 143-154. DOI. This article is @ Elsevier and permission has been granted for this version to appear in e-Publications@Marquette. Elsevier does not grant permission for this article to be further copied/distributed or hosted elsewhere without the express permission from Elsevier. 
In summary, the present study provides a foundation for future studies regarding the application of computer-based tasks of cognitive functioning to mood disorder populations. Computerized tasks can be administered by technicians and can yield valid data from the vast majority of participants within clinical and research settings. When poor performance is evident, the screening data can be sent to a consulting neuropsychologist to determine if a more thorough evaluation would be of benefit. Use of a battery of this type effectively addresses many practical limitations to collecting cognitive screening data in primary care clinics. Moreover, the present tasks have sound psychometric properties, including a factor structure that maps onto both theoretical premises and empirical findings reported in previous literature. In addition, these tasks demonstrated validity and are sensitive to attention, executive functioning, and emotion perception difficulties that were evident in the patient groups. It is possible that the tasks described in this paper will provide further insight into the functioning of brain systems known to be affected in mood disorders.

\section{Acknowledgements}

This research was supported in part by the Rachel Upjohn Clinical Scholars Award (to SAL.), NIH grant P01MH 42251 (to EAY, JKZ), internal support from the Depression and Neuropsychology Sections of the Department of Psychiatry, University of Michigan Medical Center, and the Department of Psychology, Marquette University. Some of the control $(\mathrm{N}=26)$ and depressed $(\mathrm{N}=30$ ) data included in this paper has been previously published (Langenecker et al., 2005). The aid of a number of students and assistants was invaluable in completing this project: Emily M. Anderson, Ami S. Antonucci, Andrew Benway, Rachel Burns, Korey Cantrell, Luis Casenas, Stephen Crocker, Karla Felske, Caroline Freitag, Kristen Grabar, Leslie Guidotti, B.A., Najat M. Hamid, Thomas A. Hooven, Nicole Huby, Jessica Layne, Benjamin D. Long, Justin B. Miller, Lawrence S. Own, Rebecca Reiten, Megan Shaheen, Maureen Schrock, Clare Tyson, and Lesley Weitekamp.

\section{References}

Austin et al., 1999. M.-P. Austin, P. Mitchell, K. Wilhelm. Melancholic depression: a pattern of frontal cognitive impairment. Psychological Medicine, 29 (1999), pp. 73-85

Psychiatry Research, Vol 152, No. 2-3 (August, 2007): pg. 143-154. DOI. This article is (C) Elsevier and permission has been granted for this version to appear in e-Publications@Marquette. Elsevier does not grant permission for this article to be further copied/distributed or hosted elsewhere without the express permission from Elsevier. 
NOT THE PUBLISHED VERSION; this is the author's final, peer-reviewed manuscript. The published version may be

accessed by following the link in the citation at the bottom of the page.

Beck et al., 1988. A.T. Beck, R.A. Steer, M.G. Garbin. Psychometric properties of the Beck Depression Inventory: twenty-five years of evaluation.

Clinical Psychology Review, 8 (1988), pp. 77-100

Borkowska and Rybakowski, 2001. A. Borkowska, J.K. Rybakowski.

Neuropsychological frontal lobe tests indicate that bipolar depressed patients are more impaired than unipolar. Bipolar Disorders, 3 (2001), pp. 88-94

Boustani et al., 2005. M. Boustani, C.M. Callahan, F.W. Unverzagt, M.G.

Austrom, A.J . Perkins, B.A. Fultz, S.L. Hui, H.C. Hendrie. Implementing a screening and diagnosis program for dementia in primary care. J ournal of General Internal Medicine, 20 (2005), pp. 572-577

Bush et al., 2000. G. Bush, P. Luu, M. Posner. Cognitive and emotional influences in anterior cingulate. Trends in Cognitive Neurosciences, 4 (2000), pp. 215-222

Cabeza et al., 2004. R. Cabeza, S.M. Daselaar, F. Dolcos, S.E. Prince, M. Budde, L. Nyberg. Task-independent and task-specific age effects on brain activity during working memory, visual attention and episodic retrieval. Cerebral Cortex, 14 (2004), pp. 364-375

Cohen et al., 1982. R.M. Cohen, H. Weingartner, S.A. Smallberg, D. Pickar, D.L. Murphy. Effort and cognition in depression. Archives of General Psychiatry, 39 (1982), pp. 593-598

Dickerson et al., 2004. F. Dickerson, J. Boronow, C. Stallings, A. Origoni, S. Cole, R. Yolken. Cognitive functioning in schizophrenia and bipolar disorder: comparison of performance on the Repeatable Battery for the Assessment of Neuropsychological Status. Psychiatry Research, 129 (2004), pp. 45-53

Dunkin et al., 2000. J J. Dunkin, A.F. Leuchter, I.A. Cook, J.E. Kasl-Godley, M. Abrams, S. Rosenberg-Thompson. Executive dysfunction predicts nonresponse to fluoxetine in major depression. Journal of Affective Disorders, 60 (2000), pp. 16-23

Ekman and Friesen, 1976. P. Ekman, W. Friesen. Pictures of Facial Affect. Consulting Psychologists Press. Palo Alto, CA (1976)

Ellis et al., 1989. N. Ellis, P. Woodley-Zanthos, C. Dulaney, R. Palmer. Automatic-effortful processing and cognitive inertia in persons with mental retardation. American J ournal on Mental Retardation, 93 (1989), pp. 412-423

Feiger et al., 2003. A. Feiger, M. Flament, P. Boyer, J. Gillespie. Sertraline versus fluoxetine in the treatment of major depression: a combined analysis of five double-blind comparator studies. International Clinical Psychopharmacology, 18 (2003), pp. 203-210

First et al., 1995. M.B. First, R.L. Spitzer, M. Gibbon. Structured Clinical Interview for DSM-IV Axis 1 Disorder. Biometrics Research

Psychiatry Research, Vol 152, No. 2-3 (August, 2007): pg. 143-154. DOI. This article is @ Elsevier and permission has been granted for this version to appear in e-Publications@Marquette. Elsevier does not grant permission for this article to be further copied/distributed or hosted elsewhere without the express permission from Elsevier 
Department. New York State Psychiatric Institute, New York, NY (1995)

Fisk and Rogers, 1991. A. Fisk, W. Rogers. Toward an understanding of agerelated memory and visual search effects. J ournal of Experimental Psychology: General, 120 (1991), pp. 131-149

Franke et al., 1993. P. Franke, W. Maier, J. Hardt, R. Frieboes, D. Lichterman, C. Hain. Assessment of frontal lobe functioning in schizophrenia and unipolar major depression. Psychopathology, 26 (1993), pp. 76-84

Garavan et al., 1999. H. Garavan, T. Ross, E. Stein. Right hemispheric dominance of inhibitory control: An event-related functional MRI study. Proceedings of the National Academy of Sciences of the United States of America, 96 (1999), pp. 8301-8306

Gilboa-Schechtman et al., 2002. E. Gilboa-Schechtman, D. Erhard-Weiss, P. Jeczemien. Interpersonal deficits meet cognitive biases: memory for facial expressions in depressed and anxious men and women.

Psychiatry Research, 113 (2002), pp. 279-293

Gold et al., 1999. J.M. Gold, C. Queern, V.N. Iannone, R.W. Buchanan.

Repeatable battery for the assessment of neuropsychological status as a screening test in schizophrenia: I. Sensitivity, reliability, and validity. American J ournal of Psychiatry, 156 (1999), pp. 1944-1950

Gotlib et al., 2004. I.H. Gotlib, E. Krasnoperova, D.N. Yue, J. J oormann. Attentional biases for negative interpersonal stimuli in clinical depression. Journal of Abnormal Psychology, 113 (2004), pp. 127-135

Gur et al., 1992. R. Gur, R. Edwin, R. Gur, A. Zwil, C. Heimberg, H. Kraemer. Facial emotion discrimination: II. Behavioral findings in depression. Psychiatry Research, 42 (1992), pp. 241-251

Gur et al., 2001a. R.C. Gur, D. Ragland, P. Moberg, W. Bilker, C. Kohler, S. Siegel, R.E. Gur. Computerized neurocognitive scanning: II The profile of schizophrenia. Neuropsychopharmacology, 25 (2001), pp. 777-788

Gur et al., 2001b. R.C. Gur, D. Ragland, P. Moberg, T. Turner, W. Bilker, C. Kohler, S. Siegel, R.E. Gur. Computerized neurocognitive scanning: I. Methodology and validation in healthy people. Neuropsychopharmacology, 25 (2001), pp. 766-776

Hale, 1998. WW. Hale. Judgment of facial expressions and depression persistence. Psychiatry Research, 80 (1998), pp. 265-274

Hamilton, 1960. M. Hamilton. A rating scale for depression. J ournal of Neurology, Neurosurgery and Psychiatry, 23 (1960), pp. 56-62 Hamilton, 1967. M. Hamilton. Development of a rating scale for primary depressive illness. British J ournal of Social and Clinical Psychology, 6 (1967), pp. 278-296

Hasher and Zacks, 1988. L. Hasher, R. Zacks. Working memory, comprehension and aging: a review and a new view. The Psychology of Learning and Motivation, 22 (1988), pp. 193-225

Psychiatry Research, Vol 152, No. 2-3 (August, 2007): pg. 143-154. DOI. This article is @ Elsevier and permission has been granted for this version to appear in e-Publications@Marquette. Elsevier does not grant permission for this article to be further copied/distributed or hosted elsewhere without the express permission from Elsevier. 
Hobart et al., 1999. M.P. Hobart, R. Goldberg, J.J. Bartko, J.M. Gold.

Repeatable battery for the assessment of neuropsychological status as a screening test in schizophrenia: II. Convergent/discriminant validity and diagnostic group comparisons. American Journal of Psychiatry, 156 (1999), pp. 1951-1957

Hoff et al., 1990. A. Hoff, S. Shukla, T. Aronson, B. Cook, C. Ollo, S. Baruch, L. Jandorf, J. Schwartz. Failure to differentiate bipolar disorder from schizophrenia on measures of neuropsychological function.

Schizophrenia Research, 3 (1990), pp. 253-260

Kampf-Sherf et al., 2004. O. Kampf-Sherf, Z. Zlotogorski, A. Gilboa, L.

Speedie, J. Lereya, P. Rosca, Y. Shavit. Neuropsychological functioning in major depression and responsiveness to selective seretonin reuptake inhibitors antidepressants. J ournal of Affective Disorders, 82 (2004), pp. 453-459

Kasch et al., 2002. K.L. Kasch, J. Rottenberg, B.A. Arnow, I.H. Gotlib. Behavioral activation and inhibition systems and the severity and course of depression. Journal of Abnormal Psychology, 111 (2002), pp. 589-597

Kessing, 1998. L.V. Kessing. Cognitive impairment in the euthymic phase of affective disorder. Psychological Medicine, 28 (1998), pp. 1027-1038

Kroenke et al., 2001. K. Kroenke, R.L. Spitzer, J.B.W. Williams. The PHQ-9: validity of a brief depression severity measure. Journal of General Internal Medicine, 16 (2001), pp. 606-613

Langenecker and Nielson, 2003. S.A. Langenecker, K.A. Nielson. Frontal recruitment during response inhibition in older adults replicated with fMRI. Neurolmage, 20 (2003), pp. 1384-1392

Langenecker et al., 2005. S.A. Langenecker, L.A. Bieliauskas, L.J . Rapport, J.K. Zubieta, E.A. Wilde, S. Berent. Face emotion perception and executive functioning deficits in depression. Journal of Clinical and Experimental Neuropsychology, 27 (2005), pp. 320-333

LeDoux, 2000. JE. LeDoux. Emotion circuits in the brain. Annual Review of Neuroscience, 23 (2000), pp. 155-184

Lemelin et al., 1996. S. Lemelin, P. Baruch, A. Vincent, L. Laplante, J .

Everett, P. Vincent. Attention disturbance in clinical depression:

Deficient distractor inhibition or processing resource deficit. Journal of Nervous and Mental Disease, 184 (1996), pp. 114-121

Letz et al., 1996a. R. Letz, R. Green, J. Woodard. Development of a computer-based battery designed to screen adults for neuropsychological impairment. Neurotoxicology and Teratology, 18 (1996), pp. 365-370

Letz et al., 1996b. R. Letz, W.A. Pieper, R.D. Morris. NES test performance in a large US Army Veteran sample: relationships with both demographic

Psychiatry Research, Vol 152, No. 2-3 (August, 2007): pg. 143-154. DOI. This article is @ Elsevier and permission has been granted for this version to appear in e-Publications@Marquette. Elsevier does not grant permission for this article to be further copied/distributed or hosted elsewhere without the express permission from Elsevier. 
factors and traditional neuropsychological measures. Neurotoxicology and Teratology, 18 (1996), pp. 381-390

Madden et al., 2004. D.J. Madden, W.L. Whiting, J.M. Provenzale, S.A. Huettel. Age-related changes in neural activity during visual target detection measured by fMRI. Cerebral Cortex, 14 (2004), pp. 143-155

Martinez-Aran et al., 2004. A. Martinez-Aran, E. Vieta, M. Reinares, F. Colom, C. Torrent, J. Sanchez-Moreno, A. Benabarre, J. Goikolea, M. Comes, M. Salamero. Cognitive function across manic or hypomanic, depressed, and euthymic states in bipolar disorder. American J ournal of Psychiatry, 161 (2004), pp. 262-270

Mayberg et al., 1999. H.S. Mayberg, M. Liotti, S. Brannan, S. McGinnis, R. Mahurin. Reciprocal limbic-cortical function and negative mood: converging PET findings in depression and normal sadness. American J ournal of Psychiatry, 156 (1999), pp. 675-682

Miller et al., 2004. J.B. Miller, S.A. Langenecker, A. Freymuth, C.P. Persad, K.A. Nielson. Validity of the conditional Go/No-go task. Journal of the International Neuropsychological Society. Supplement, Conference Proceedings, Baltimore, MD (2004)

Naismith et al., 2003. S. Naismith, I. Hickie, K. Turner, C. Little, V. Winter, P. Ward, K. Wilhelm, P. Mitchell, G. Parker. Neuropsychological performance in patients with depression is associated with clinical, etiological and genetic risk factors. Journal of Clinical and Experimental Neuropsychology, 25 (2003), pp. 866-877

Nielson et al., 2002. K.A. Nielson, S.A. Langenecker, H. Garavan. Differences in the functional neuroanatomy of inhibitory control across the adult lifespan. Psychology and Aging, 17 (2002), pp. 56-71

Nutt, 2001. D. Nutt. Neurobiological mechanisms in generalized anxiety disorder. J ournal of Clinical Psychiatry, 62 (2001), pp. S22-S27

Pizzigalli et al., 2001. D. Pizzigalli, R.D. Pascual-Marqui, J. Nitschke, T.R. Oakes, C.L. Larson, H. Abercrombie, S. Schaefer, JV. Koger, R. Benca, R. Davidson. Anterior cingulate activity as a predictor of degree of treatment response in major depression: Evidence from brain Electrical Tomography Analysis. American J ournal of Psychiatry, 158 (2001), pp. 405-415

Rapport et al., 2002. L.J . Rapport, S. Friedman, A. Tzelepis, A. VanVoorhis. Experienced emotion and effect recognition in adult attention-deficit hyperactivity disorder. Neuropsychology, 16 (2002), pp. 102-110

Robbins et al., 1994. T.W. Robbins, M. James, A.M. Owen, B.J. Sahakian, L. Mclnnes, P. Rabbitt. Cambridge Neuropsychological Test Automated Battery (CANTAB): a factor analytic study of a large sample of normal elderly volunteers. Dementia, 5 (1994), pp. 266-281

Rohling et al., 2002. M.L. Rohling, P. Green, L. Allen, G.L. Iverson. Depressive symptoms and neurocognitive test scores in patients passing sympotm

Psychiatry Research, Vol 152, No. 2-3 (August, 2007): pg. 143-154. DOI. This article is @ Elsevier and permission has been granted for this version to appear in e-Publications@Marquette. Elsevier does not grant permission for this article to be further copied/distributed or hosted elsewhere without the express permission from Elsevier 
NOT THE PUBLISHED VERSION; this is the author's final, peer-reviewed manuscript. The published version may be accessed by following the link in the citation at the bottom of the page.

validity tests. Archives of Clinical Neuropsychology, 17 (2002), pp. 205-222

Schatzberg et al., 2000. A.F. Schatzberg, J.A. Posener, C. DeBattista, B.M. Kalehzan, A.J. Rothschild, P.K. Shear. Neuropsychological deficits in psychotic versus nonpsychotic major depression and no mental illness. American Journal of Psychiatry, 157 (2000), pp. 1095-1100

Shipley, 1946. W.C. Shipley. Institute of Living Scale. Western Psychological Services, Los Angeles, CA (1946)

Simpson et al., 1989. P.M. Simpson, K. Wesnes, L. Christmas. A computerised system for the assessment of drug induced performance changes in young elderly or demented populations. British Journal of Clinical Pharmacology, 27 (1989), pp. 711-712

Sweeney et al., 2000. J.A. Sweeney, J.A. Kmiec, D.J . Kupfer. Neurological impairments in bipolar and unipolar mood disorders on the CANTAB Neurocognitive Battery. Biolological Psychiatry, 48 (2000), pp. 74-685

Tabachnik and Fidell, 2001. B. Tabachnik, L. Fidell. Using Multivariate Statistics. (4th ed.), Allyn and Bacon, Boston, MA (2001) Williams et al., 2000. R.A. Williams, B.M. Hagerty, B. Cimprich, B. Therrien, E. Bay, H. Oe. Changes in directed attention and short-term memory in depression. Journal of Psychiatry Research, 34 (2000), pp. 227-238 